\title{
46. CORRELATION OF ACOUSTIC STRATIGRAPHY WITH CORED LITHOLOGY BY MEANS OF PHYSICAL PROPERTY DATA FOR DEEP SEA DRILLING PROJECT SITES 511, 513, AND 514, LEG 71 ${ }^{1}$
}

\author{
Ulf Bayer and Rolf Ott, Institut fur Geologie und Paläontologie, Universität Tübingen, \\ Tübingen, Federal Republic of Germany
}

\begin{abstract}
Physical property data make possible fine-scale stratigraphic correlation of seismic reflection profiles with core lithology. Data from Sites 513 and 514 show that pronounced, subparallel reflector banding corresponds to fluctuations in the clay content of diatomaceous oozes. Data from Site 511 indicate that diagenetic alterations of the sediment may influence the reflection pattern.
\end{abstract}

During Leg 71, we recognized a very closely spaced, subparallel reflection pattern in the Tertiary diatomaceous sediments and in two acoustic units of the Mesozoic sequence at Site 511 . The pattern did not correlate with lithology in any obvious fashion. Some of the closely spaced reflectors may represent sound source reverberations (see the site chapters), which may cause difficulties in detecting primary reflections. Lithologic and acoustic impedance contrasts are small, although numerous, within the acoustic layers in question, but within the extremely constant velocity profiles in diatomaceous oozes $(1.6 \mathrm{~km} / \mathrm{s})$, even small impedance changes may allow short-path multiples to build up enough energy to be recognized in the seismic record (Anstey, 1977). The changing anisotropy of sediments may also influence the acoustic pattern, as was found from the stressstrain behavior of the vane shear test (Bayer, this volume). Furthermore, Richards and Young (1980) hypothesize that bioturbation alters acoustic properties. The information required for a complete geoacoustic model involves a large number of physical and sedimentological parameters (Hamilton, 1980) and a detailed knowledge of the seismic source. For Leg 71, we have in some cases only rough estimates; information is also missing. Instead of giving a geoacoustic model, therefore, we have undertaken an empirical analysis of the available data. In particular, we have ignored problems associated with the acoustic source.

To obtain a detailed correlation of the seismic and lithological profiles, physical property and smear slide data were analyzed on shore and compared to the seismic record. Coring disturbance generates many problems for the detailed analysis of physical property data, as Bennett and Keller (1973) have described. Although the physical property data are biased, the laboratory sonic velocity and impedance measurements are the best data available for correlating the seismic and lithological profiles. A simple simulation of reflectivity derived

\footnotetext{
${ }^{1}$ Ludwig, W. J., Krasheninnikov, V. A., et al., Init. Repts. DSDP, 71: Washington (U.S. Govt. Printing Office).
}

from physical properties was used to attempt a correlation for Sites 511, 513, and 514. The basic problem for the correlation is the transformation of two-way travel time into depth. Using the sonic velocity measurements, the transformation function was computed from the differential equation for the velocity.

$$
\dot{V}(x)=2 \mathrm{~d} x / \mathrm{d} t
$$

where $\dot{V}(x)=$ measured sonic velocity, by integrating the equation

$$
t=2 \int_{X_{1}}^{X_{2}} \mathrm{~d} x / V(x)
$$

numerically, using the simple trapezoid rule. For a more objective interpretation of the impedance $I$, where $I$ $\left[\mathrm{g} /\left(\mathrm{cm}^{2} \mathrm{~s}\right)\right] \cdot 10^{5}=$ sonic velocity $[\mathrm{km} / \mathrm{s}] \cdot$ wet-bulk density $\left[\mathrm{g} / \mathrm{cm}^{3}\right]$, the reflection coefficient $R$ was computed as

$$
R=\frac{\text { (impedance of layer } 2)-(\text { impedance of layer } 1)}{\text { (impedance of layer } 2)+(\text { impedance of layer } 1)}
$$

where layer 1 overlies layer 2 .

The term layer has no meaning within the sequences under discussion here, because there are no criteria for subdividing them into lithological subunits ("layers"). Instead of using the simple concept of the reflection coefficient as Anstey (1977) did, therefore, we have viewed the reflection coefficient as a tool for estimating the boundaries of sonic units from the impedance data. The impedance profiles defined on irregularly distributed sample points were redefined on a regularly spaced grid by linear interpolation, whereby the depth points were spaced more closely than the smallest spacing between samples. Under these conditions, the magnitude of the reflection coefficient computed from the estimated data becomes a function of the step between depth points, and the reflection coefficient gives only relative values of reflected energy. Furthermore, the estimated depth 
position of the reflecting boundary and its width will vary with changes in the depth distribution of data. As the distance between the estimated impedance points decreases, the computed position of the reflecting boundary will move toward the upper measured sample point.

The graphic representations, numeric integration, computation of reflectivity, and search for extrema in the reflection curve were done using a computer program written by $\mathbf{R}$. Ott.

The computed reflection patterns for Sites 511, 513, and 514 are summarized in Table 1.

\section{SITE 511}

The sonic velocities (see Bayer, this volume) and the impedance values (Fig. 1) for Site 511 indicate three major acoustic units:

Unit I (0-200 m; Lithological Units 1 and 2) shows very constant impedance values. The recovery during this unit was poor and only major changes are recognizable.

Unit II (200-500 m; Lithological Units 3, 4, and 5) shows slowly increasing impedance values with some superposed peaks.

Unit III (500-632 m: Lithological Unit 6) shows in its upper part strongly fluctuating impedance values.

Recovery within Acoustic Unit I was too poor to give data indicative of the details of the reflection pattern. The boundary between Acoustic Units I and II corresponds to locally increased impedance values within the upper part of the Cretaceous sequence. These high impedance values correspond to a change in sediment com-

Table 1. Depth versus one-way travel time (1WTT) for the simulated reflection pattern at estimated reflection boundaries.

\begin{tabular}{|c|c|c|c|c|c|}
\hline \multicolumn{2}{|c|}{ Site 511} & \multicolumn{2}{|c|}{ Site 513} & \multicolumn{2}{|c|}{ Site 514} \\
\hline $\begin{array}{l}\text { Depth } \\
\text { (m) }\end{array}$ & $\begin{array}{l}\text { 1WTT } \\
(\mathrm{m} / \mathrm{s})\end{array}$ & $\begin{array}{c}\text { Depth } \\
\text { (m) }\end{array}$ & $\begin{array}{l}\text { 1WTT } \\
(\mathrm{m} / \mathrm{s})\end{array}$ & $\begin{array}{c}\text { Depth } \\
\text { (m) }\end{array}$ & $\begin{array}{l}\text { 1WTT } \\
(\mathrm{m} / \mathrm{s})\end{array}$ \\
\hline 36.2 & 39.5 & 20.1 & 23.7 & 2.7 & 1.7 \\
\hline 101.8 & 120.7 & 39.1 & 47.4 & 4.8 & 4.3 \\
\hline 140.2 & 167.2 & 50.1 & 61.1 & 7.8 & 8.0 \\
\hline 177.5 & 231.7 & 55.9 & 68.4 & 12.0 & 13.3 \\
\hline 205.2 & 249.3 & 66.7 & 81.9 & 18.8 & 21.8 \\
\hline 250.5 & 293.5 & 72.9 & 89.7 & 21.3 & 24.9 \\
\hline 270.3 & 316.1 & 96.0 & 118.8 & 30.2 & 36.3 \\
\hline 290.3 & 338.4 & 103.4 & 128.3 & 34.7 & 41.9 \\
\hline 301.9 & 351.2 & 104.7 & 129.9 & 50.6 & 61.7 \\
\hline 357.0 & 404.3 & 111.0 & 137.8 & 56.5 & 69.0 \\
\hline 412.5 & 467.0 & 118.6 & 147.4 & 65.7 & 80.5 \\
\hline 433.8 & 490.3 & 135.2 & 168.0 & 68.4 & 83.9 \\
\hline 448.0 & 505.7 & 175.8 & 219.3 & 98.7 & 121.9 \\
\hline 494.4 & 551.9 & 180.4 & 225.1 & 100.2 & 123.7 \\
\hline 500.9 & 559.3 & 204.3 & 255.3 & 107.7 & 133.2 \\
\hline 514.0 & 571.6 & 222.3 & 277.8 & 112.6 & 139.3 \\
\hline 528.1 & 582.7 & 223.3 & 279.1 & 118.0 & 146.0 \\
\hline \multirow{7}{*}{597.7} & 657.5 & 230.1 & 287.6 & 130.1 & 161.1 \\
\hline & & 260.4 & 325.3 & 137.6 & 170.5 \\
\hline & & 323.3 & 403.0 & 138.4 & 171.6 \\
\hline & & 343.0 & 426.9 & 140.9 & 174.7 \\
\hline & & 354.0 & 440.4 & 145.6 & 180.4 \\
\hline & & 356.0 & 442.9 & & \\
\hline & & 364.1 & 452.9 & & \\
\hline
\end{tabular}

position (Fig. 1). The additional components occurring within this section include abundant zeolites and especially large amounts of unspecified, nonbiogenic carbonates. The increased impedance, therefore, is due to diagenetic alterations. We conclude that the seismic reflector corresponds to these sediments and not primarily to the Cretaceous/Tertiary boundary, which is somewhat higher in the profile and is associated with a hiatus. Within Acoustic Unit II, a rapid change of impedance values occurs at approximately 350 meters depth. It has no visible correspondence with a change in the sedimentological composition, but corresponds with a region of reduced porosity values (Fig. 2). Acoustic Unit II passes from an area of closely spaced reflectors into a reflection-free section. This pattern roughly corresponds to closely spaced fluctuations of the $\mathrm{CaCO}_{3}$ content in the upper part of the unit and a more uniform distribution of the $\mathrm{CaCO}_{3}$ content within the nannofossil oozes in the lower part. Closely spaced lithologic fluctuations occur again in the upper part of Acoustic Unit III, and these correspond to fluctuating impedance values and possibly to the closely spaced reflector pattern. This lithologic sequence also contains large amounts of unspecified carbonate, the presence of which indicates diagenetic cementation. Thus, empirically, it seems likely that the subparallel reflection patterns within the Mesozoic sequence of Site 511 correspond to lithologically stratified sequences and that diagenetic changes may strongly influence the acoustic pattern.

\section{SITE 513}

The closely spaced, subparallel reflection configuration observed on the seismic record in the area of Site 513 allowed us to correlate this pattern with lithology using the physical property data. These lithological units have been recorded for Site 513:

Unit 1: 180 meters of muddy diatomaceous oozes.

Unit 2: 53.9 meters of muddy diatomaceous nannofossil ooze and diatomaceous nannofossil ooze.

Unit 3: 145.5 meters of nannofossil ooze containing some indurated chalk zones.

The impedance-depth log (Fig. 3) shows numerous sharp but small impedance contrasts within Lithological Unit 1 that correlate with fluctuations in the diatomclay content. The peaks of the computed relative reflection coefficient are very sharp as a result of the computation method, which tends to associate high reflectivities with rapid changes of the impedance and lower reflectivities with gradually changing impedance values. The simulation (Fig. 3) shows a very good correspondence between the reflectors of the seismic record and the computed reflection pattern. Thus it is likely that the seismic stratification correlates with a lithological stratification caused by fluctuations in the diatom and clay content of the sediments. Within the recorded depth range, changes in clay content affect the physical properties of diatomaceous oozes much more than does compaction (Bayer, this volume).

The boundary between Lithologic Units 1 and 2 can be clearly correlated with the seismic record, as can a 


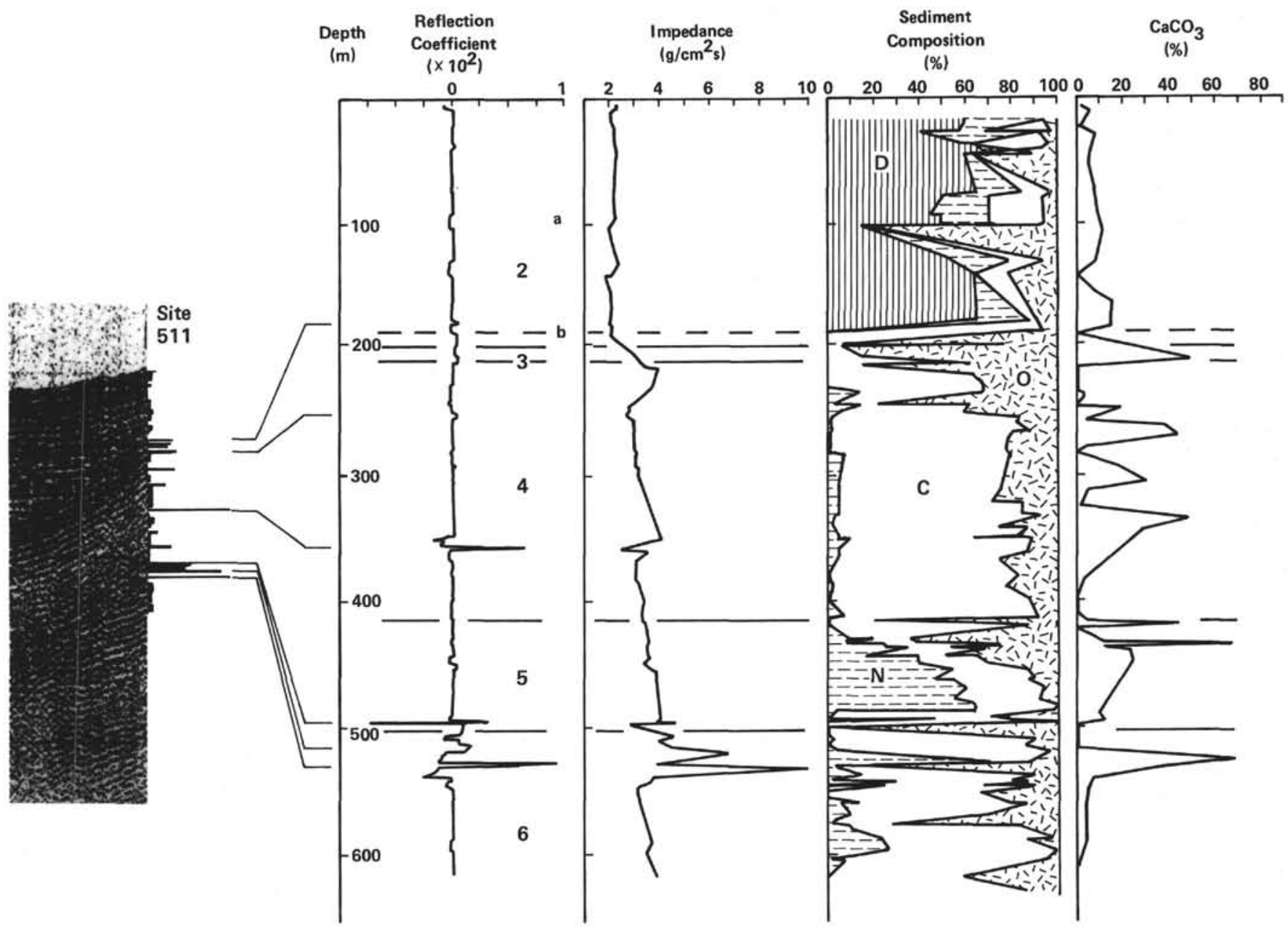

Figure 1. Correlation of seismic record, lithology, and simulated reflection pattern derived from physical properties data for Site 511 . $(\mathrm{N}=$ nannofossils, $\mathrm{D}=$ diatoms, $\mathrm{C}=$ clay, $\mathrm{O}=$ other components; Arabic numbers indicate lithological units.)

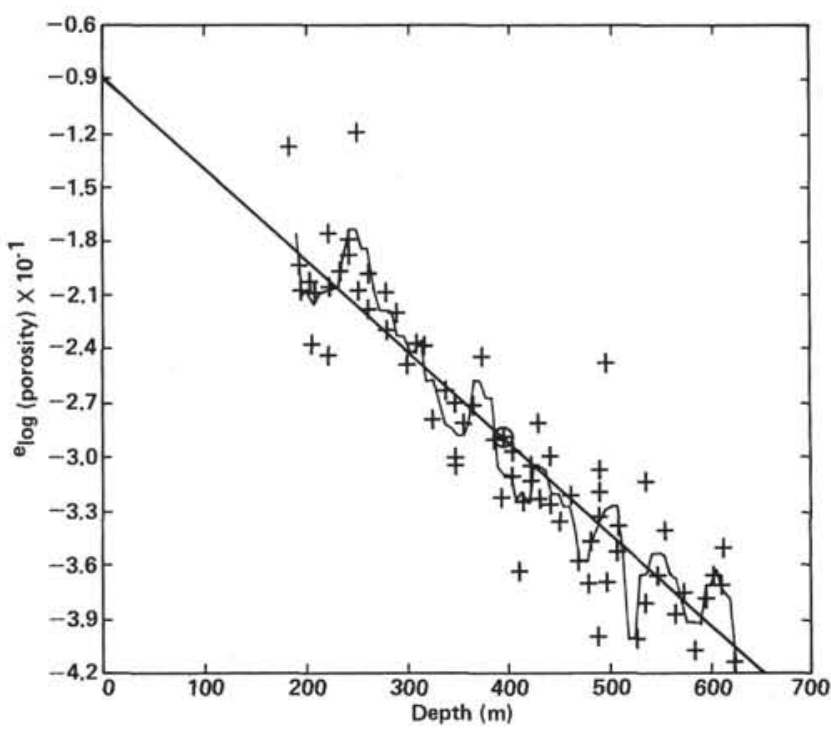

Figure 2. The linearized relationship of ${ }^{\mathrm{e}} \log$ (porosity) and depth for the Mesozoic sequence of Site 511. (Crosses are data points; the trend line was estimated from an unweighted moving average [area of influence $10 \mathrm{~m}$ ]; and the straight line was fitted by least squares.) short interval of diatomaceous oozes between Units 2 and 3. Within the nannofossil oozes of Units 2 and 3 , some stratification occurs in the seismic record, although the configuration is not as parallel as in Unit 1. Recovery in Unit 3 was very poor, and there are not enough impedance data to simulate a detailed reflection pattern. Given that the reflection pattern of Unit 2 can be related to composition and therefore to carbonate content, one may assume that the seismic pattern of Unit 3 corresponds to the indurated chalk zones which occur in this sequence.

\section{SITE 514}

In principle, the penetration depth of Site 514 is too low for a correlation with the seismics. But the seismic record closely resembles that of Site 513, and the lithologic composition is also very similar. Furthermore, physical property data were taken for small intervals, so a possible correlation can be given in Figure 4 . The simulated reflection pattern indicates two reflector horizons between 0 and 30 meters depth and between 100 and 140 meters depth, and these fit very well the seismic record. Furthermore, the substructure of these reflection zones is closely approximated by the simulated re- 


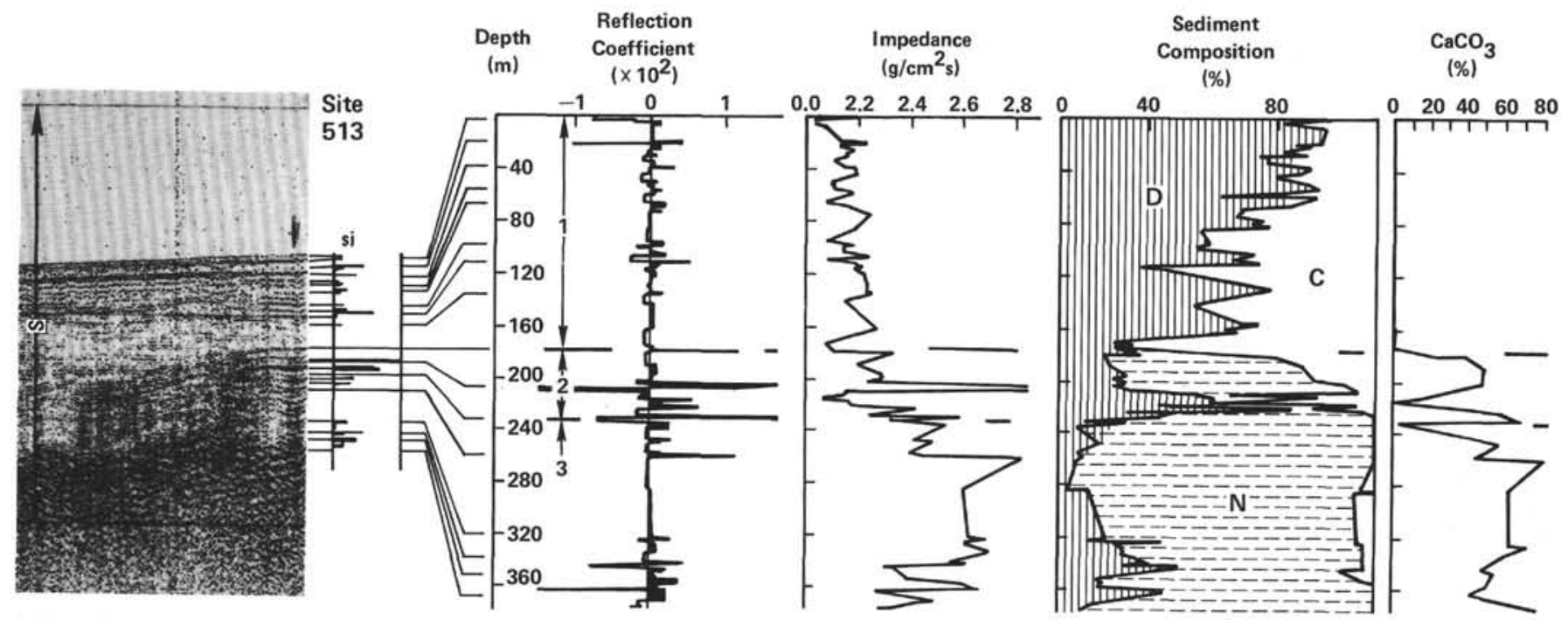

Figure 3. Correlation of seismic record, lithology, and simulated reflection pattern for Site 513. $(\mathrm{N}=$ nannofossils, $\mathrm{D}=$ diatoms, $\mathrm{C}=$ clay; $\mathrm{N}+\mathrm{D}+\mathrm{C}=100 \%$; other components are not shown. Arabic numbers indicate lithological units.)

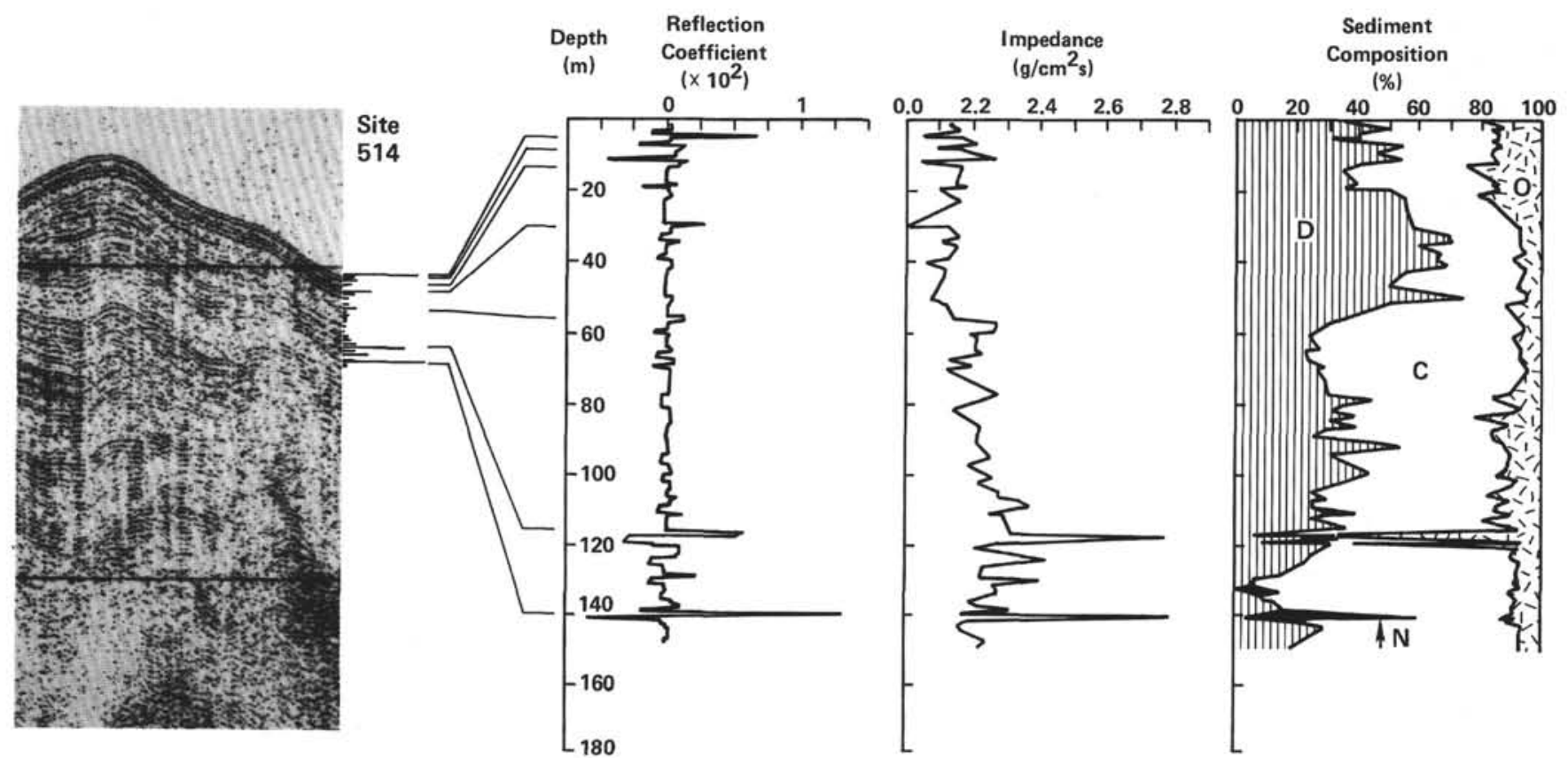

Figure 4. Correlation of seismic record, lithology, and simulated reflection pattern for Site 514 . $(\mathrm{N}=$ nannofossils, $\mathrm{D}=$ diatoms, $\mathrm{C}=$ clay,
$\mathrm{O}=$ other components.)

flection pattern (Fig. 4). Again the impedance contrasts are small, but they correlate very well with lithologic changes-fluctuations in clay content within the upper reflection zone and the occurrence of nannofossil-enriched sediments in the lower reflection zone. Empirically then, the closely spaced, subparallel reflection pattern in the young diatomaceous oozes can be related with high probability to compositional fluctuations within this sediment type.

Impedance and reflectivity in diatomaceous sediments with a diatom content of more than $40 \%$ are particularly sensitive to fluctuations of the clay content. The some- what more pronounced reflection pattern of Site 513 corresponds to a diatom content that is even higher. This finding agrees very well with those of Mayer (1980), who found that "variations in acoustic impedance are almost entirely controlled by changes in saturated bulk density (porosity)," which, again, is correlated with the sedimentological composition.

\section{ACKNOWLEDGMENTS}

Drs. G. Einsele and A. Wetzel of the Institut für Geologie und Paläontologie, Universität Tübingen, and Drs. R. Flood, W. Ludwig, and A. Shor, Lamont-Doherty Geological Observatory, critically read the manuscript and made valuable comments. 


\section{REFERENCES}

Anstey, N. A., 1977. Seismic Interpretation: The Physical Aspects: Boston (International Human Resources Development Corp.), pp. 134-140.

Bennett, R. H., and Keller, G. H., 1973. Physical properties evaluation. In van Andel, Tj. H., Heath, G. R., et al., Init. Repts. DSDP, 16: Washington (U.S. Govt. Printing Office), 513-519.
Hamilton, E. L., 1980. Geoacoustic modeling of the sea floor. $J$. Acoust. Soc. Am., 68(5):1313-1340.

Mayer, L. A., 1980. Deep-sea carbonates: Physical property relationships and the origin of high-frequency acoustic reflectors. Mar. Geol., 38:165-183.

Richards, M. D., and Young, D. K., 1980. Geoacoustic models and bioturbation. Mar. Geol., 38:205-218. 